\title{
Cancers attributable to reproductive factors in the UK in 2010
}

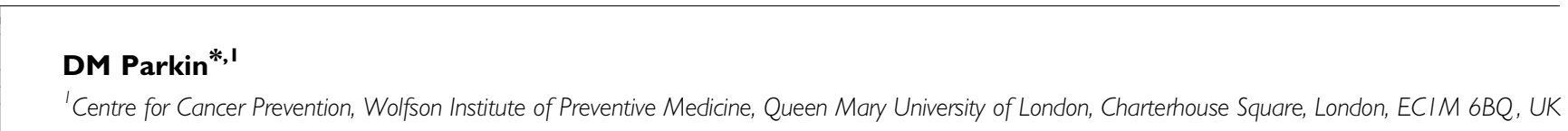

British Journal of Cancer (201I) I 05, S73-S76; doi:I0.1038/bjc.20II.488 www.bjcancer.com

(C) 20II Cancer Research UK

Reproductive factors influence the risk of cancers of the female genital tract (uterus and ovary) and breast. The following reproductive factors are important in this respect: age at menarche; age at first birth; parity; age at menopause; and duration of breastfeeding. The effects of exogenous hormones are described in Section 10.

\section{Age at menarche}

Early age at menarche has been consistently associated with an increased risk of breast and endometrial cancer (Pike et al, 2004). Relative risk (RR) for premenopausal breast cancer is reduced by an estimated $7 \%$ for each year that menarche is delayed after age 12 years, and by $3 \%$ for post-menopausal breast cancer (Clavel-Chapelon, 2002). The effect on risk is through prolongation of the period with relatively high exposure to endogenous oestrogen.

\section{Age at first birth}

The younger the woman is when she begins childbearing, the lower her risk of breast cancer (Kelsey et al, 1993). The RR of developing breast cancer increases by $3 \%$ for each year of delay (Collaborative Group, 2002).

\section{Parity}

Increasing parity reduces the risk of breast, endometrial and ovarian cancers (Pike et al, 2004). The higher the number of fullterm pregnancies, the greater the protection. Compared with nulliparous women, a woman who has at least one full-term pregnancy reduces her risk of breast cancer by around 25\% (Layde et al, 1989; Ewertz et al, 1990) and women with five or more children experience a $50 \%$ reduction in risk (Kelsey et al, 1993). For endometrial cancer, risk is reduced by $30 \%$ for a woman's first birth and by $25 \%$ for each successive birth, and later maternal age at last birth has also been shown to reduce the risk (Pike et al, 2004). For ovarian cancer, risk in women with four pregnancies is only $40 \%$ that in nulliparous women (Ness et al, 2002). However, increasing parity increases the risk of cancer of the cervix, independently of any increase in the prevalence of infection with HPV (Munoz et al, 2002).

\footnotetext{
*Correspondence: Professor DM Parkin; E-mail: d.m.parkin@qmul.ac.uk
}

\section{Age at menopause}

Late menopause increases the risk of breast cancer and endometrial cancer (Pike et al, 2004). For breast cancer, risk is doubled for a woman with menopause at 55 years compared with less than 45 years (Kelsey et al, 1993). For each year that the menopause is delayed, there is an approximate $3 \%$ increase in breast cancer risk (Collaborative Group, 1997). Postmenopausal women have a lower risk of breast cancer compared with premenopausal women of the same age, both for natural menopause and for menopause induced through surgery (Collaborative Group, 1997).

\section{Breastfeeding}

The role of breastfeeding as a protective factor against the later development of breast cancer has been long suspected (LaneClaypon, 1926). More recently, this association has been confirmed and the magnitude of the effect estimated as a decrease in risk of $4.3 \%$ for every 12 months of breastfeeding (Collaborative Group on Hormonal Factors in Breast Cancer, 2002). For ovarian cancer, the issue is less clear. An early collaborative analysis of casecontrol studies found a reduced risk in parous women who had ever breastfed compared with those who had never done so (Whittemore et al, 1992). Subsequent work suggested that only serous tumours may be so influenced (Jordan et al, 2007, 2008). A recent analysis of two US cohort studies (Danforth et al, 2007) suggests that each month of breastfeeding reduces the RR by $2 \%$ $(\mathrm{RR}=0.98$ per month, 95\% CI $0.97-1.00)$.

Although a woman's reproductive behaviour can influence the risk of cancers of the uterus, ovary and breast, most of the important aspects discussed above are not sensibly considered as targets for preventive interventions.

In this section, therefore, only the cancers attributable to suboptimal levels of breastfeeding are evaluated.

\section{METHODS}

Breastfeeding of infants in Britain is not very common, and is generally not prolonged for more than a few weeks. Surveys of infant feeding in the UK, at 5-yearly intervals since 1975, have been carried out by the Department of Health. The most recent survey (the seventh) was in 2005 (Bolling et al, 2007). Table 1 shows the results of these surveys. 
Table I Percentage of women breastfeeding at given intervals post partum (Great Britain)

\begin{tabular}{lcccccc}
\hline & \multicolumn{5}{c}{ \% Women breastfeeding, by year of survey } \\
\cline { 2 - 7 } & & & & & & \\
$\begin{array}{l}\text { Interval post } \\
\text { partum }\end{array}$ & $\mathbf{1 9 8 0}$ & $\mathbf{1 9 8 5}$ & $\mathbf{1 9 9 0}$ & $\mathbf{1 9 9 5}$ & $\mathbf{2 0 0 0}$ & $\mathbf{2 0 0 5}$ \\
\hline Birth & 65 & 63 & 62 & 66 & 69 & 76 \\
I Week & 54 & 52 & 51 & 56 & 55 & 63 \\
2 Weeks & 51 & 49 & 48 & 53 & 52 & 60 \\
6 Weeks & 41 & 39 & 39 & 42 & 42 & 48 \\
4 Months & 27 & 27 & 26 & 27 & 28 & 34 \\
6 Months & 21 & 20 & 20 & 21 & 21 & 25 \\
8 Months & 15 & 14 & 14 & 15 & 16 & 21 \\
9 Months & 14 & 13 & 13 & 14 & 13 & 18 \\
\hline
\end{tabular}

Values in italics have been interpolated.

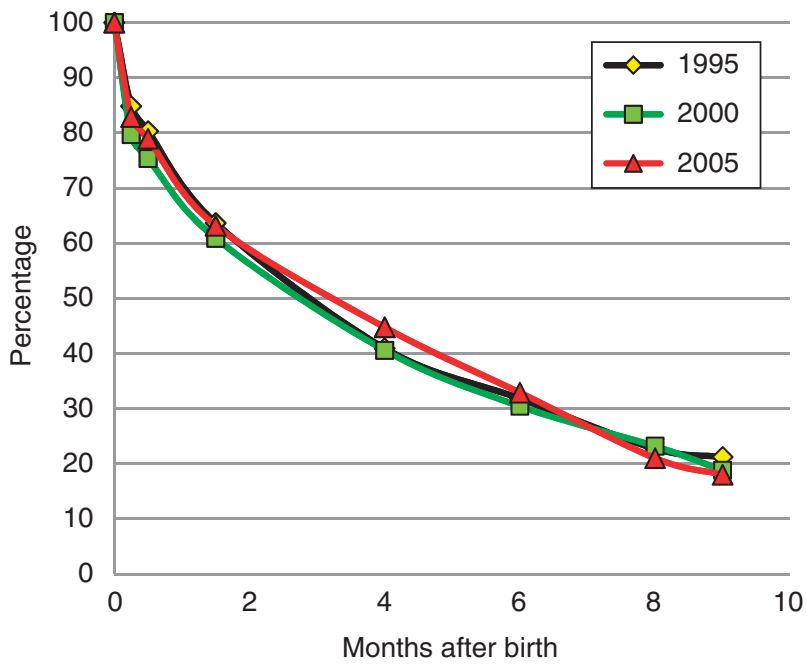

Figure I Percent of women continuing breastfeeding, by time since birth.

The values in italics have been interpolated. This seems relatively secure, as the decline in breastfeeding prevalence with time since birth in women who do actually commence seems to be relatively constant (Figure 1).

There is no generally accepted target for breastfeeding. The Global Strategy on Diet, Physical Activity and Health of the World Health Organisation (WHO, 2004) includes a recommendation to 'promote and support exclusive breastfeeding for the first six months of life and promote programmes to ensure optimal feeding for all infants and young children'. Therefore, we have taken as the optimum breastfeeding of all live-born children for six months, with no change to the current pattern after this time. Currently, some $18 \%$ of women are breastfeeding to 9 months of age (Table 1)

Table 2 gives information on the birth experience of women in England and Wales in 2008, the most recent year available (Office for National Statistics, 2009).

Table 3 shows the estimated duration of breastfeeding (based on the data of Table 1).

With a change in risk for each month of breastfeeding of $-0.366 \%$ for breast cancer and $-2.0 \%$ for ovarian cancer (Collaborative Group on Hormonal Factors in Breast Cancer, 2002; Danforth et al, 2007), the actual protection provided by the breastfeeding practices of each generation of women can be estimated (column 1 of Table 4). The breastfeeding practices from
Table 2 Natality of women in England and Wales in 2008, by age/birth cohort

\begin{tabular}{|c|c|c|c|c|}
\hline $\begin{array}{l}\text { Age } \\
\text { (years) }\end{array}$ & $\begin{array}{l}\text { Central } \\
\text { birth } \\
\text { year }\end{array}$ & $\begin{array}{c}\text { Average } \\
\text { number } \\
\text { of live-born } \\
\text { children }\end{array}$ & $\begin{array}{l}\text { Average age } \\
\text { when } 50 \% \\
\text { children had } \\
\text { been born }\end{array}$ & $\begin{array}{c}\text { Average year } \\
\text { when } \mathbf{5 0 \%} \\
\text { children had } \\
\text { been born }\end{array}$ \\
\hline $0-4$ & 2006 & 0 & - & - \\
\hline $5-9$ & 2001 & 0 & - & - \\
\hline $10-14$ & 1996 & 0 & - & - \\
\hline $15-19$ & |99| & 0.04 & 13 & 2004 \\
\hline $20-24$ & 1986 & 0.34 & 19 & 2003 \\
\hline $25-29$ & 1981 & 0.80 & 23 & 2001 \\
\hline $30-34$ & 1976 & 1.34 & 26 & 1999 \\
\hline $35-39$ & $197 \mid$ & 1.75 & 26 & 1996 \\
\hline $40-44$ & 1966 & 1.90 & 26 & |99| \\
\hline $45-49$ & $196 \mid$ & 1.96 & 27 & 1985 \\
\hline $50-54$ & 1956 & 2.02 & 26 & 1980 \\
\hline $55-59$ & $195 \mid$ & 2.04 & 25 & 1974 \\
\hline $60-64$ & 1946 & 2.19 & 25 & 1968 \\
\hline $65-69$ & $194 \mid$ & 2.34 & 25 & 1964 \\
\hline $70-74$ & 1936 & 2.40 & 26 & 1960 \\
\hline $75-79$ & 1931 & 2.35 & 27 & 1956 \\
\hline $80-84$ & 1926 & 2.12 & 27 & 1951 \\
\hline$\geqslant 85$ & 1921 & 2.00 & 27 & 1946 \\
\hline
\end{tabular}

Table 3 Median and mean duration of breast feeding (Great Britain)

\begin{tabular}{lcccccc}
\hline & \multicolumn{5}{c}{$\begin{array}{c}\text { Duration of breastfeeding (months) } \\
\text { by year of survey }\end{array}$} \\
\cline { 2 - 7 } Average & $\mathbf{1 9 8 0}$ & $\mathbf{1 9 8 5}$ & $\mathbf{1 9 9 0}$ & $\mathbf{1 9 9 5}$ & $\mathbf{2 0 0 0}$ & $\mathbf{2 0 0 5}$ \\
\hline Median & 0.60 & 0.48 & 0.38 & 0.84 & 0.71 & 1.46 \\
Mean & 2.84 & 2.75 & 2.71 & 2.89 & 2.90 & 3.50 \\
Mean if all $\geqslant 6$ months $^{\mathrm{a}}$ & 6.78 & 6.75 & 6.74 & 6.79 & 6.78 & 7.02 \\
\hline
\end{tabular}

aMean if all women could breastfeed their children for 6 months (so prevalence at 6 months is 100\%).

Table 1 are assumed to apply to the year in which $50 \%$ of the children in a given age group in 2008 would have been born. Since there are no data on breastfeeding practices prior to 1980 , the duration of having been breastfed for women in the age groups $\geqslant 55-59$ are taken to be the same as in 1980 .Table 3 also shows the estimated mean duration of breastfeeding if all women could breastfeed their children for 6 months (so that prevalence at 6 months is $100 \%$ ), after which the values in Table 1 continue to pertain.

\section{RESULTS}

Column 1 of Table 4 shows the decrease in risk of breast and ovarian cancer due to breastfeeding, of women in the UK, by age group, in 2008, and column 2 the decrease in risk if all had been breastfed for a minimum of 6 months. Column 3 shows the excess risk of women in 2008, due to their breastfeeding practice being short of target, and column 4 the population-attributable fraction of breast and ovarian cancer cases by age.

In Table 5, we assume that the RR estimated for 2008 is pertinent for 2010, and show the actual numbers of cancer cases that would be attributable to breastfeeding practices not reaching the optimum level.

In total 2699 cancer cases projected to occur in 2010 (1498 breast cancers, 1201 ovarian cancers) would have been avoided if breastfeeding practice had been at the theoretical 'optimum'. This 
Table 4 Effect of breastfeeding on women's risk of breast and ovarian cancer, UK 2008

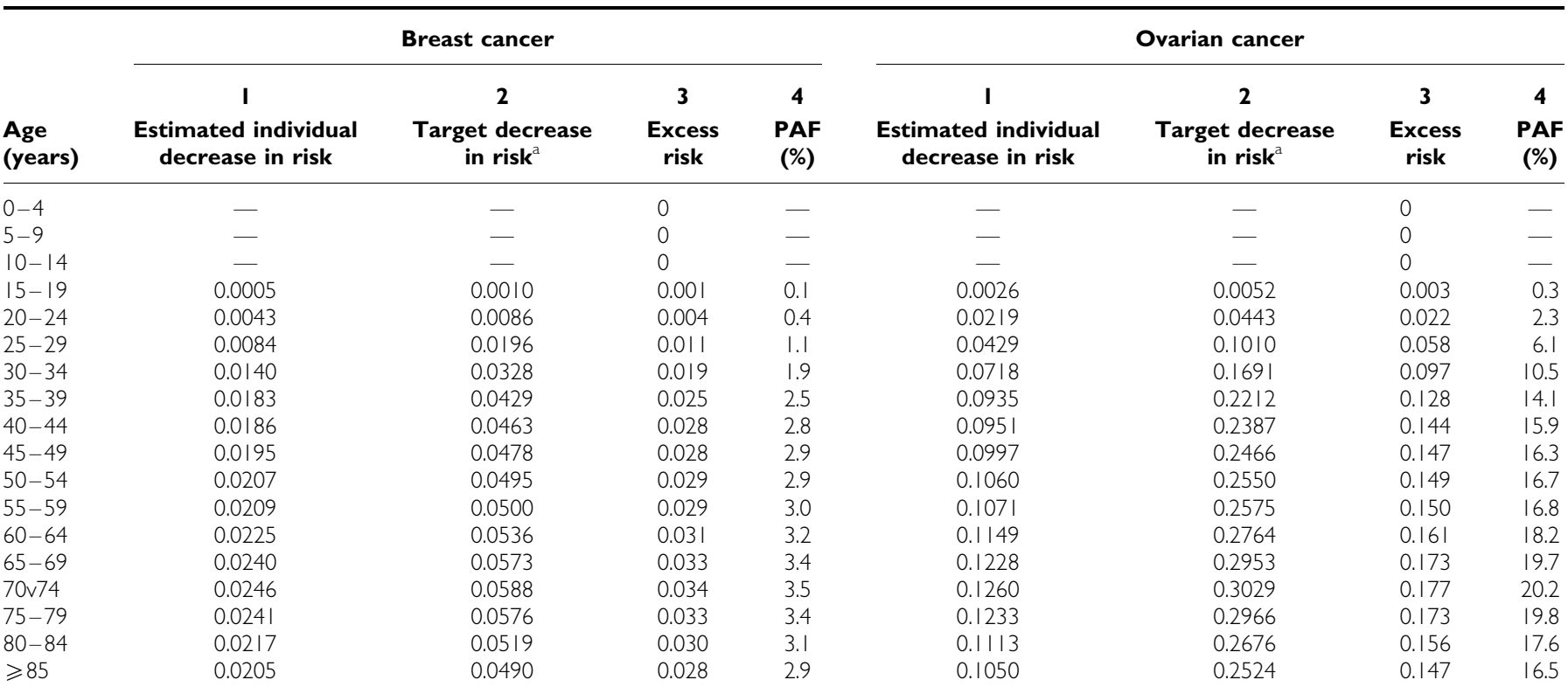

Abbreviation: PAF = population-attributable fraction. alf all had breastfed for a minimum of 6 months.

Table 5 Cases of breast and ovarian cancer estimated to be due to sub-optimal breast feeding, UK 2010

\begin{tabular}{|c|c|c|c|c|c|c|c|c|}
\hline $\begin{array}{l}\text { Age } \\
\text { (years) }\end{array}$ & \multicolumn{4}{|c|}{ Breast } & \multicolumn{4}{|c|}{ Ovary } \\
\hline $5-9$ & I & 0 & 0 & - & I & 4 & 2 & - \\
\hline $10-14$ & I & 0 & 0 & - & 1 & 6 & 3 & - \\
\hline $15-19$ & 1.0005 & 4 & 0 & 0.1 & 1.0026 & 23 & 0 & 0.3 \\
\hline $30-34$ & 1.0194 & 548 & 10 & 1.9 & 1.1171 & 103 & 11 & 10.5 \\
\hline $35-39$ & 1.0258 & 1265 & 32 & 2.5 & 1.1639 & 160 & 23 & 14.1 \\
\hline $40-44$ & $|.029|$ & 2593 & 73 & 2.8 & 1.1885 & 278 & 44 & 15.9 \\
\hline $45-49$ & 1.0298 & 4236 & 123 & 2.9 & 1.1950 & 428 & 70 & 16.3 \\
\hline $50-54$ & 1.0303 & 4810 & $14 \mid$ & 2.9 & 1.1999 & 498 & 83 & 16.7 \\
\hline $55-59$ & 1.0306 & 5582 & 166 & 3.0 & 1.2026 & 623 & 105 & 16.8 \\
\hline $60-64$ & 1.0329 & 6459 & 206 & 3.2 & 1.2232 & 883 & 161 & 18.2 \\
\hline All ages & & 48385 & 1498 & 3.1 & & 6820 & $120 \mid$ & 17.6 \\
\hline
\end{tabular}

Abbreviation: PAF $=$ population-attributable fraction.

represents $1.7 \%$ of cancers in women and $0.9 \%$ of all cancer cases in 2010.

\section{DISCUSSION}

Though it may be desirable, from the point of view of cancer prevention, to have multiple pregnancies commencing at a young age, there are equally, or more, persuasive reasons to avoid such a lifestyle. It makes no sense, therefore, to prescribe an ideal fertility pattern, against which the number of cancers attributable to a less optimum one can be evaluated. In the IARC calculation of avoidable cancers in France (IARC, 2007), the fertility pattern of 1980 was taken as an ideal against which the excess cases resulting from fertility in 2000 were calculated, although the rationale for this was not explained. The origin of the Doll and Peto (2003) estimate of $15 \%$ of UK cancer deaths being attributable to 'reproduction' (and other factors related to the secretion of reproductive hormones) is obscure; the methodology is said to be the same as in their 1981 monograph (Doll and Peto, 1981), although this considers some $46 \%$ of the deaths due to cancers of the breast, ovary and uterus (corpus and cervix) as attributable to reproductive and sexual factors, and these cancers are responsible for only $8 \%$ of cancer deaths in UK in 2005. 
It is reasonable, however, to advocate breastfeeding for a variety of reasons, of which the benefit of cancer protection is one (http:// www.breastfeeding.nhs.uk/en/fe/page.asp? $1=2)$. The 'optimum' levels for breastfeeding against which attributable fractions of breast and ovarian cancer have been evaluated are rather artificial, in that it would be impossible for all women to breastfeed their infant for 6 months. In the United States, for example, the US Department of Health and Human Services (2005) Healthy People 2010 objectives for breastfeeding initiation and duration were to increase the proportion of mothers who exclusively breastfeed their infants through age 3 months to $60 \%$ and through

\section{REFERENCES}

Bolling K, Grant C, Hamlyn B, Thornton A (2007) Infant Feeding Survey 2005. http://www.ic.nhs.uk/pubs/ifs200

Clavel-Chapelon F (2002) Differential effects of reproductive factors on the risk of pre- and postmenopausal breast cancer. Results from a large cohort of French women. Br J Cancer 86: 723-727

Collaborative Group on Hormonal Factors in Breast Cancer (1997) Breast cancer and hormone replacement therapy: collaborative reanalysis of data from 51 epidemiological studies of 52705 women with breast cancer and 108411 women without breast cancer. Collaborative Group on Hormonal Factors in Breast Cancer. Lancet 350: 1047-1059

Collaborative Group on Hormonal Factors in Breast Cancer (2002) Breast cancer and breastfeeding: collaborative reanalysis of individual data from 47 epidemiological studies in 30 countries, including 50302 women with breast cancer and 96973 women without the disease. Lancet 360: $187-195$

Danforth KN, Tworoger SS, Hecht JL, Rosner BA, Colditz GA, Hankinson SE (2007) Breastfeeding and risk of ovarian cancer in two prospective cohorts. Cancer Causes Control 18: 517-523

Doll R, Peto R (1981) The Causes of Cancer: Quantitative Estimates of Avoidable Risks of Cancer in the United States Today. Oxford University Press: Oxford

Doll R, Peto R (2003) The epidemiology of cancer. In Oxford Textbook of Medicine, Warrell DA, Cox TM, Firth JD, Benz EJ (eds) 4th edn, Chapter 6.1, pp 193-218. Oxford University Press: Oxford

Ewertz M, Duffy SW, Adami HO, Kvåle G, Lund E, Meirik O, Mellemgaard A, Soini I, Tulinius H (1990) Age at first birth, parity and risk of breast cancer: a metaanalysis of 8 studies from the Nordic countries. Int J Cancer 46: 597-603

International Agency for Research on Cancer (IARC) (2007) Attributable Causes of Cancer in France in the Year 2000. IARC Working Group Reports, Vol. 3. IARC: Lyon

Jordan SJ, Green AC, Whiteman DC, Moore SP, Bain CJ, Gertig DM, Webb PM (2008) Serous ovarian, fallopian tube and primary peritoneal cancers: a comparative epidemiological analysis. Int $J$ Cancer 122: $1598-1603$

Jordan SJ, Green AC, Whiteman DC, Webb PM, Australian Ovarian Cancer Study Group (2007) Risk factors for benign, borderline and invasive mucinous ovarian tumors: epidemiological evidence of a neoplastic continuum? Gynecol Oncol 107: 223-230

Kelsey JL, Gammon MD, John EM (1993) Reproductive factors and breast cancer. Epidemiol Rev 15: 36-47 age 6 months to 25\%. Exclusive breastfeeding is defined as an infant receiving only breast milk and no other liquids or solids except for drops or syrups consisting of vitamins, minerals or medicines (WHO, 1991). Clearly, the target for partial breastfeeding may be more ambitious, so that the target may not be so very far from the theoretical optimum, advocated by WHO.

See acknowledgements on page $\mathrm{Si}$.

\section{Conflict of interest}

The author declares no conflict of interest.
Lane-Claypon JE (1926) A Further Report on Cancer of the Breasts, with Special Reference to its Associated Antecedent Conditions. Report on Public Health and Medical Subjects No. 32. HMSO: London

Layde PM, Webster LA, Baughman AL, Wingo PA, Rubin GL, Ory HW (1989) The independent associations of parity, age at first full term pregnancy, and duration of breastfeeding with the risk of breast cancer. Cancer and Steroid Hormone Study Group. J Clin Epidemiol 42: 963-973

Munoz N, Franceschi S, Bosetti C, Moreno V, Herrero R, Smith JS, Shah KV, Meijer CJ, Bosch FX, International Agency for Research on Cancer Multicentric Cervical Cancer Study Group (2002) Role of parity and human papillomavirus in cervical cancer: the IARC multicentric case-control study. Lancet 359: 1093-1101

Ness RB, Cramer DW, Goodman MT, Kjaer SK, Mallin K, Mosgaard BJ Purdie DM, Risch HA, Vergona R, Wu AH (2002) Infertility, fertility drugs, and ovarian cancer: a pooled analysis of case-control studies. Am J Epidemiol 155: 217 -224

Office for National Statistics (2009) Birth Statistics Review of the National Statistician on births and patterns of family building in England and Wales, 2008 (Series FM1 No. 37). http://www.ons.gov.uk/ons/publications/ re-reference-tables.html?edition $=\mathrm{tcm} \% 3 \mathrm{~A} 77-226270$

Pike MC, Pearce CL, Wu AH (2004) Prevention of cancers of the breast, endometrium and ovary. Oncogene 23: 6379-6391

US Department of Health and Human Services (2005) Healthy People 2010 midcourse review. US Department of Health and Human Services: Washington, DC. http://www.healthypeople.gov/data/midcourse

Whittemore A, Harris R, Itnyre J (1992) Characteristics relating to ovarian cancer risk: collaborative analysis of 12 US case-control studies. II. Invasive epithelial ovarian cancers in white women. Collaborative Ovarian Cancer Group. Am J Epidemiol 136: 1184-1203

World Health Organization (WHO) (1991) Indicators for Assessing Breastfeeding Practices. World Health Organization: Geneva, Switzerland. http://whqlibdoc.who.in/hq/1991/WHO_CDD_SER_91.14.pdf

World Health Organisation (WHO) (2004) Global Strategy on Diet, Physical Activity and Health (WHA57.17). http://www.who.int/dietphysicalactivity/ strategy/eb11344/strategy_english_web.pdf

cc)(-) () This work is licensed under the Creative Commons cc. ${ }_{\mathrm{BY}} \mathrm{NC}_{\mathrm{SA}}$ Attribution-NonCommercial-Share Alike 3.0 Unported License. To view a copy of this license, visit http://creativecommons. org/licenses/by-nc-sa/3.0/ 